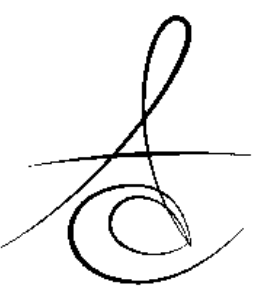

\section{HERBST APAREYİ İLE YAPILAN ORTODONTİK TEDAVİDE KARŞILAŞILAN KOMPLIKASYONLAR}

\section{COMPLICATIONS ENCOUNTERED IN ORTHODONTIC TREATMENT WITH} THE HERBST APPLIANCE

Prof. Dr. Elçin ESENLİK*
Uzm. Dr.Esra YÜKSEL COŞKUN**

\author{
Makale Kodu/Article code: 4363 \\ Makale Gönderilme tarihi; 06.04 .2020 \\ Kabul Tarihi: 02.10.2020 \\ DOI : $10.17567 /$ ataunidfd. 804264
}

Elçin Esenlik : ORCID ID: 0000-0002-5647-4630

Esra Yüksel Coşkun : ORCID ID: 0000-0002-0233-785X

\title{
öz
}

Mandibular retrognatinin mevcut olduğu hastalarda, mandibular büyüme stimülasyonu için çeşitli ortopedik apareylerden faydalanılmaktadır. Herbst apareyi, bu amaçla kullanılan sabit fonksiyonel ortopedik apareylerden biridir ve farklı tasarımlarla kullanılabilmektedir. Bu tedavi yöntemi ile hastanın yaşına ve büyüme-gelişim dönemine göre farklı etkiler elde edilebilmektedir. Apareylerin tasarım ve uygulanmasına bağlı olarak tedavi süresince; bant kırıması, bandın kaybolması, teleskop parçasının kırıması, splint kaybı ve splint kırılması, vida gevşemesi, piston deformasyonu ve akrilik parçanın kırılması ve yumuşak doku yaralanmaları gibi komplikasyonlarla karşılaşıırken; tedavi sonunda ise aşırı alt kesici diş protrüzyonu ve spee eğrisinin artması gibi durumlarla da karşılaşılabilmektedir. Kök rezorpsiyonu ve kondiler rezorpsiyona yol açtığı konusunda ise bilimsel bir kanıt henüz bulunmamaktadır. Bu derlemenin amacı Herbst apareyinin çeşitli tasarımlarıyla yapılan tedavi sırasında ve sonrasında karşılaşılan komplikasyonları sunmaktır.

Anahtar Kelimeler: Ortodontik aletler, fonksiyonel; Herbst apareyi; Komplikasyonlar

\section{ABSTRACT}

Various orthopedic appliances are used for mandibular growth stimulation in patients with mandibular retrognathia. Herbst appliance is one of the fixed functional orthopedic appliances used for this purpose and it can be used with different modifications. Different effects can be obtained depending on the patient's age and growth and development stages with this treatment. Complications based on the design and application of the appliance such as band breakage, band loss, telescope breakage, splint loss, and splint breakage, screw loosening, piston deformation and acrylic fracture and soft tissue injuries can be encountered, whereas, excessive lower incisor protrusion and increased curve of spee can be seen at the end of treatment. However there is no evidence about its inducing root resorption and condylar resorption The aim of this review was to present the complications encountered during and after treatment with various designs of the Herbst appliance.

Key words: Orthodontic appliances, functional; Herbst Appliance; Complications

${ }^{*}$ Ortodonti AD, Akdeniz Üniversitesi Diş Hekimliği Fakültesi, Antalya, Türkiye

**Uzman Ortodontist, Isparta, Türkiye

Kaynakça Bilgisi: Esenlik E, Yüksel Coşkun E. Herbst apareyi ile yapılan ortodontik tedavide karşılaşılan komplikasyonlar. Atatürk Üniv Diş Hek Fak Derg 2021; 31: 471-80.

Citation Information: Esenlik E, Yuksel Coskun E. Complications encountered in orthodontic treatment with the herbst appliance. J Dent Fac Atatürk Uni 2021; 31: 471-80.

\section{GİRİş}

Herbst apareyi, Sınıf II mandibular retrognatili bireylerde uygulanan sabit fonksiyonel apareyler içinde, bilindiği kadarıyla ilk olarak sunulan aparey olup, 1909'da Berlin'deki 5. Uluslararası Diş Hekimliği Kongresi'nde tanıtılmıştır ve sonrasında bu konuda çeşitli çalışmalar yapılmıştır. 1934'ten sonra Herbst apareyi oldukça az kullanılmış ve hakkında çok az çalışma yayınlanmıştır. Ancak 1970'lerin sonunda Dr. Pancherz tarafından yeniden bu tedavi yöntemi gündeme getirilmiş ve hakkında birçok çalışma yapılmıştır. ${ }^{1}$

Herbst apareyi, mandibular kondiler büyümeyi uyarmayı amaçlar ve bu nedenle özellikle retrognatik mandibulanın mevcut olduğu Sınıf II anomalilerin tedavisinde tercih edilebilmektedir. ${ }^{2-4}$ Birçok çalışmada Herbst apareyinin iskeletsel Sınıf II anomalilerin tedavilerinde kullanılan etkili yöntemlerinden olduğu rapor edilmiştir. ${ }^{5-10}$ Herbst apareyi, maksilla ve mandi- bula arasında olan yapay bir ekleme benzetilmektedir. Çift 
taraflı teleskop sistem; mandibulayı beslenme, konuşma, çiğneme, ısırma ve yutkunma gibi fonksiyonlar sırasında sürekli önde konumlandırmaktadır. ${ }^{1}$ Mandibular büyümeyi stimüle edici etkisinin yanı sıra üst çene büyümesinin sınırlandırılmasına, alt çenede mesial, üst çenede distal yönlü diş hareketlerine neden olduğu belirtilmiştir. ${ }^{2}$

Pancherz'in orijinal bantlı tasarımı, zamanla modifiye edilerek farklı şekillerde kullanılmaya başlanmıştır. Destek dişlerdeki ortodontik bantlar yerine paslanmaz çelik kronlar kullanılan döküm Herbst apareyi de tekrar modifiye edilerek, hem maksiller hem de mandibular diş arklarında, mandibular aktivasyon kuvvetlerine dayanacak akrilik splintlerden oluşan splint Herbst'ler şeklinde yeniden tasarlanmıştır. ${ }^{11}$ Herbst apareyi, üst ve alt bileşenlere sahip olduğu için genişletme intiyacına bağlı olarak üst parçaya Hyrax tipi rapid maksiller ekspansiyon vidası lehimlenmesine izin verir. Bir piston, apareyin üst bileşeninden alt bileşene uzanır ve alt çeneyi daha öne doğru sürekli olarak yönlendirir. Bu nedenle mandibular büyüme stimulasyonu sağlanır ve overbite da azaltılmış olur. ${ }^{9}$

Herbst apareyi ile diğer fonksiyonel ortopedik apareylerde olduğu gibi, overjet eliminasyonunun hem iskeletsel hem de dişsel değişimlerin sonucunda olduğu bilinmektedir. İskeletsel değişikliklerin oranının erken dönemde tedavi edilen hastalarda daha fazla olduğu, geç büyüme döneminde yapılanlarda ise dişsel değişimlerin daha belirgin olduğu rapor edilmektedir. $6,7,12-14$ Herbst tedavisi sonucunda oluşan iskeletsel ve dişsel değişimler, yumuşak dokuları da etkilemektedir ve tedavi sonrasında hastaların profilinde iyileşme olduğu bildirilmektedir. ${ }^{15,16}$

Temel olarak, Herbst apareyi ile başarılı bir tedavi için, maksiller ve mandibular dişlerin iyi hizalanması ve diş pozisyonlarının özellikle sagittal yönde normal pozisyonda olması istenmektedir. Hareketli fonksiyonel ortopedik apareylerin aksine, Herbst apareyinin avantajları aşağıda belirtildiği şekilde özetlenmektedir: ${ }^{6}$

1-Herbst apareyi dişlere sabitlendiği için hastadan herhangi bir yardım almadan günde 24 saat kesintisiz çalışır. Bu nedenle kooperasyonu zayıf olan hastalarda rahatlıkla kullanılabilir.

2-Herbst apareyiyle tedavi, post-pubertal hastalarda 6 ile 8 ay içerisinde tamamlanabilir ve böylece büyüme atılımını geçmiş olan bu hastalarda, büyümegelişim dönemi bitmeden önce kondiler büyüme stimülasyonunu mümkün kılar.

3- Herbst apareyi, nazal hava yolu tıkanıkIıklarının mevcut olduğu durumlarda, hareketli apareylerin aksine kullanımda bir problem yaratmaz.
Herbst apareyinin tüm bu etkileri ve avantajlarına rağmen, birtakım dezavantajları ve tedavi sırasında karşılaşılan komplikasyonları da bulunmaktadır. Bu komplikasyonların bazıları literatürde rapor edilmiştir. Daha önce rapor edilen komplikasyonlar ve klinik tecrübelerimize dayanan gözlemler bu derlemede özetlenmeye çalışılacaktır. Herbst apareyi ile tedavi sırasındaki komplikasyonlar değerlendirildiğinde, apareyin dizaynına bağlı olarak komplikasyon paterninin de değiştiği anlaşılmaktadır. ${ }^{17-21}$ Herbst komplikasyonları başlıca aparey dizaynlarına bağlı komplikasyonlar (bant, piston, splint kırıması vb.), kök rezorpsiyonu, alt kesici dişlerde protrüzyon, yumuşak doku yaralanmaları, TME ile ilgili komplikasyonlar ve relaps başıkları altında incelenebilir.

\section{Herbst Apareyi Kullanımı ile Oluşan Komplikasyonlar}

Herbst tedavisi sırasında en sıklıkla karşılaşılan komplikasyonlar apareyi oluşturan parçaların kırılması, kopması veya kaybolması şeklinde olmaktadır. Bandın kırılması ya da kaybolması, teleskop parçanın ya da pistonun kırılması, splint destekli Herbst dizaynlarında splintin kaybı veya kırıması, akrilik parçanın kırılması ve vidanın gevşemesi en sık gözlenen ve rapor edilen komplikasyonlardandır. Bu konuda yapıımış sınırlı çalışmaların sonuçları aşağıda özetlenmeye çalışılmıştır:

\section{1-Aparey parçalarından kaynaklı} komplikasyonlar:

Hagg ve ark. Herbst apareyleri üzerine yapmış oldukları çalışmalarında bantlı Herbst apareylerinin, splint destekli Herbst apareylerinden daha fazla kırılma olasılığı bulunduğunu, splintlilerin de yerinden çıkma eğiliminde olduğunu bildirmişlerdir. Uygulama kolaylığı bakımından bu iki dizayn karşılaştırıldığında, splint destekli Herbst apareylerinin bantlı Herbst apareylerine göre, hastaya uyumlandırılması için daha az klinik zaman ve daha az laboratuvar zamanı gerektirdiği tespit edilmiştir. Bununla beraber bantlı Herbst apareylerinin ise daha kalıcı olduğu rapor edilmiştir. Bu çalışma sonucunda splint destekli olanlarla klinik ve laboratuvar sürecinde zaman tasarrufu sağlandığı belirtilmiştir. ${ }^{18}$

Schiöth ve ark. tarafından kısaltılmış (reduced) mandibular döküm splint (RMS) uygulanmış 50 hasta ile total mandibular döküm splint uygulanmış 182 Herbst apareyi uygulanmış hastada komplikasyon prevalansı ve tipi incelenmiştir. ${ }^{22}$ Total mandibular splintli Herbst'lerde molar ve kanin dişlerin arasında yer alan döküm splintler lingual barla birbirlerine bağlıyken, kısaltılmış splintli (döküm) Herbst'lerde ikinci premolar ve kanin dişleri arasında yer alan döküm splintler, lingual arkla birbirlerine bağlanarak 
tasarlanmıştır. Bu dizaynın total splintler kadar etkili ve daha ekonomik olduğu belirtilmiştir. ${ }^{20}$ Total mandibular splint grubunda \%60 oranında komplikasyon görülürken, benzer şekilde kısaltılmış mandibular splint grubunda \%58 oranında komplikasyon görüldüğünü bildirmişlerdir. En fazla karşılaşılan problemler ise maksiller ve mandibuler splint kayıpları, splint kırılması ve teleskop kırılmasıdır. Splint boyutunun küçültülmesi bu bakımdan bir avantaj sağlamamıştır. Splint kaybı en sık karşılaşılan durum olup, kısa splint grubunda $\% 56,3$ oranında, total mandibular splint grubunda ise $\% 66,9$ oranında görülmüştür. En sık rastlanan ikinci komplikasyon tipi ise mandibular splintin kırılması olup, kısaltılmış mandibular splint grubundaki komplikasyonların \%32,5'ini ve total mandibular splint gru bundakilerin \%26,8'ini oluşturmuştur. Ayrıca, kısaltılmış splint grubunda iki kat daha fazla teleskop kırılması gözlenmiştir.22 Aynı çalışmada hastalar komplikasyon sıklığına göre dört kategoriye ayrılmıştır: düşük sıklıkta (1-3 komplikasyon), orta sıklıkta (4-6 komplikasyon), yüksek sıklıkta (7-10 komplikasyon) ve çok yüksek sıklıkta (> 10 komplikasyon) olmak üzere sınıflandırımıştır. Hastaların çoğunda sadece birkaç komplikasyon olmasına rağmen, çok sayıda problemi olan bazı bireyler de olduğu bildirilmiştir. Kısaltılmış splintli grubun \%80'inin ve total splint grubunun \%56'sının düşük komplikasyon sıklığı gösterdiği rapor edilmiştir. Orta derecede komplikasyon sıklığı ise kısaltılmış splint grubunda \%10, total splint grubunda ise \%31 oranında görülmüştür. Yüksek sıklıkta komplikasyon ise her iki grupta da benzer olarak sırasıyla \%10 ve \%12 oranlarında görülmüştür. Total mandibular splint grubunda 1 hastada çok yüksek sıklıkta komplikasyon görülürken, diğer grupta vaka bildirilmemiştir. Kısa mandibular splint ile yapılan Herbst tedavisi sonucunda komplikasyon prevalansı değişmezken, komplikasyon sıklığını ve maliyetini azalttığı için daha çok tavsiye edilmektedir. ${ }^{22}$

Farklı dizaynlarda Herbst apareyi uygulanmış 316 hastanın değerlendirildiği diğer bir çalışmada da karşılaşılan komplikasyonlar incelenmiştir. ${ }^{19} \mathrm{Bu}$ hastaların 134'ü bantlı Herbst apareyi ile 182'si ise döküm splint Herbst apareyi ile tedavi edilmiştir. Bantlı Herbst hastalarının 44'ünde hiçbir komplikasyon görülmezken, diğer hastalarda komplikasyona rastlanmıştır. \%17,4 oranında maksiller bant kırı̆ı̆, $\% 12,4$ oranında mandibular bant kırığı, \%5,8 oranında teleskop kırıması, \%42,2 oranında maksiller bant kaybı ve \%22,2 oranında mandibular bant kaybı görülmüştür. Splint tipi grupta ise 182 hastanın \%40'ında hiçbir komplikasyon bildirilmezken, geriye kalan hastalarda bazı komplikasyonlar görülmüştür. Bunların \%8'inde maksiller splint kırığı, \%1,3'ünde mandibular splint kırıkları, \%4,3'ünde teleskop kırılması, \%66,9'unda maksiler splint kaybı ve $\% 26,8$ 'inde mandibular splint kaybı olduğu rapor edilmiştir. Özellikle splint kayıplarının yüksek oranda olduğu göze çarpmaktadır. ${ }^{19}$

Wiechmann ve ark. lingual tedavi ile kombine modifiye Herbst tedavisi uygulanan 35 bireyde karşılaşılan komplikasyonları değerlendirmişlerdir. Bu modifikasyonda ataşmanlar alt kanin ve birinci premolar dişler ile üst ikinci premolar ve birinci azı dişlerinin bukkaline kompozit yapıştırıcılar yardımıyla lingual tedaviden bağımsız olarak yerleştirilmektedir. Bireylerin 25'inde \%71,4'ünde hiçbir komplikasyon gözlenmezken, 10 vakada toplam 13 komplikasyon bildirilmiştir. Bunlardan 5'i üst molarda tamir edilebilir $L$ pin fraktürü iken, 8'i ise kompozit kopmasına bağlı Herbst apareyi ataçmanı kaybı olduğu rapor edilmiştir. Hiçbir vakada teleskop kırığı ve vida gevşemesi bildirilmemiştir. Bu çalışmada komplikasyonlar nitelik olarak hafif ve şiddetli olarak ikiye ayrılmıştır. Eğer komplikasyonlar hazır komponentlerin tekrar takılması ya da irritasyon kaynaklarının çıkarılması gibi kolay ve karmaşık olmayan bir yeniden yapılandırma ise hafif, bireyselleştirilmiş parçaların kırılması ya da gevşemesi durumunda şiddetli olarak adlandırımıştır. Çoğu komplikasyonun basit klinik yöntemlerle tamir edilebilecek seviyede olduğu bildirilmiştir. Tüm komplikasyonlar değerlendirdiğinde komplikasyonsuz tedavi yüzdesinin; ilk 100 gün için \%88, 200 gün için $\% 70$ ve 300 gün için \%56,8 olduğu rapor edilmiştir. Ciddi komplikasyonlar için ortalama komplikasyonsuz tedavi süresinin 27 ay olduğu bildirilmiştir. ${ }^{23}$

Manni ve ark. yaptıkları çalışmalarında, sırasıyla splint tipi Herbst apareyi ile tedavi edilmiş 155 ve HTH tipi Herbst apareyi ile tedavi edilmiş 53 hastayı değerlendirmişlerdir. Hastalarda oluşan komplikasyonlar; yerinden çıkmış Herbst, kırılmış ve onarılmış Herbst, kırılmış ve yeniden yapılmış Herbst (acil durumlar), hasta işbirliğinin olmaması nedeniyle yeniden yapılması gereken Herbst ve çıkarılması gereken Herbst (tedavi başarısızlığı) olarak belirlenmiştir. HTH tipi Herbst'ün fonksiyonel olarak bozulma riskinin daha düşük olduğu; akrilik splint Herbst'ün, HTH tipi Herbst'ten iki kat kadar daha yüksek oranda acil durum komplikasyon oranına sahip olduğu belirtilmiştir. ${ }^{24}$

Silva ve ark. hareketli akrilik splint Herbst ve cantilever Herbst $(\mathrm{CH})$ uygulanan 159 hastada en sık görülen komplikasyonları değerlendirmişlerdir. $\mathrm{CH}$ tipi Herbst; üst ve alt molar dişlerde olmak üzere dört pas- 
lanmaz çelik kron, üst molar dişler arası transpalatal ark, alt birinci küçük azı dişlerde okluzal restli bir lingual ark ve alt premolar dişler arasında cantilever Herbst'ün mesial ucuna yerleştirilmiş kalın bir koldan oluşan Herbst tasarımıdır. ${ }^{25,26}$ Bu farklı dizaynlar değerlendirildiğinde, $\mathrm{CH}$ grubunda \%35,3 oranında vida gevşemesinin meydana geldiği ve \%29,4 oranında piston deformasyonunun gerçekleştiği rapor edilmiştir. Hareketli akrilik splint Herbst grubunda ise $\% 43,2$ oranında vida gevşemesiyle karşılaşıldığı ve \%34,4 oranında da akrilik kırılmasının görüldüğü bildirilmiştir. ${ }^{27}$

Manni ve ark. yaptıkları çalışmalarında, 90 kısa mandibular splint (RMS) tipi Herbst apareyi ile 89 MTH tipi Herbst apareyi ile tedavi edilmiş hastaları değerlendirmişlerdir. MTH tipi Herbst'ün RMS tipi Herbst'e göre, geri dönüşümlü komplikasyonlarda (apareyin yeniden yapılmasını gerektirmeyen komplikasyonlar) daha düşük oranda komplikasyon yüzdesi gösterdiği (\%20,2'ye karşı \%51,1), iki grup arasında geri dönüşümsüz komplikasyonlar (apareyin çıkarılması ve yeniden yapılması gereken) açısından istatistiksel olarak anlamlı bir fark bulunmadığı belirtilmiştir. Geri dönüşümsüz komplikasyonların tümü, RMS tipi Herbst grubunda, geri dönüşümlü komplikasyonlardan sonra ortaya çıkarken; MTH tipi Herbst grubundaki geri dönüşümsüz komplikasyonların çoğunun, daha önceden oluşmuş geri dönüşümlü bir komplikasyon olmadan ortaya çıktığı bildirilmiştir. ${ }^{28}$ Resim 1 'de geri dönüşümlü komplikasyonlara tipik bir örnek olarak 4 kez Herbst apareyi desimante olan bir vakanın ağız içi fotoğrafı gösterilmektedir.

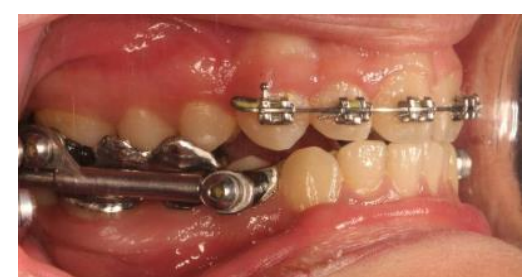

Resim 1. Herbst apareyi desimante olan bir vakanın ağız içi fotografi

\section{Yumuşak doku yaralanmaları}

Herbst apareyi kullanımına bağlı oluşan mukoza yaralanmalarının oranı yaklaşık \%12 olarak bildirilmiştir. Bu durumun diğer fonksiyonel apareylere göre düşük-orta bir insidansta olduğu, ancak Herbst komplikasyonları arasında önemli bir yeri olduğu belirtilmiştir. 25,29 Bunlardan bir tanesi piston uzunluğuyla ilgilidir. Piston uzunluğu, ağız geniş açıldığında tüpün dışına kaymasını önlemek için maksimumda tutulur. Piston çok uzun olursa, tüpün çok gerisine uzanabil- mekte ve üst daimi birinci molar dişin distalindeki bukkal mukozayı yaralayabilmektedir. ${ }^{6}$ Teleskopik Herbst'lerin tasarlanmasıyla klinik yönetimin kolaylaştığı, ancak hasta için konforun azaldığı belirtilmiştir. ${ }^{25}$ Herbst Miniscope ve HTH tipi Herbst kullanımıyla dekübit ülser sayısında bir artış olduğu bildirilmiştir. ${ }^{25}$ Mandibulanın lateral hareketleri sırasında oral mukozanın ülseratif lezyonlarını azaltmak için silindirin arka kısmı MTH tipi Herbst'te kısaltılmış, düzleştirilmiş ve eğimlendirilmiştir. ${ }^{28}$ Resim 2a-c'de Herbst kullanımı sonrası yumuşak dokuda meydana gelen irritasyonlardan birine örnek bir vaka gösterilmektedir.
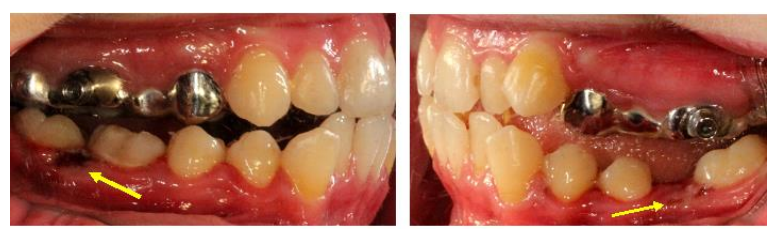

Resim 2a,b.

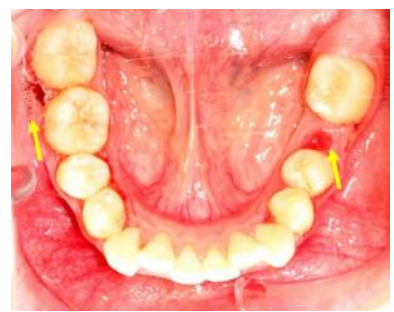

Resim 2c.

Manni ve ark.'nın RMS tipi Herbst ve MTH tipi Herbst apareylerini karşılaştırdıkları çalışmalarında, iki grupta da hiçbir hastada apareyin çıkarılmasını gerektiren ciddi ülseratif lezyonlar gelişmediği, RMS tipi Herbst grubunda sadece bir hastada rahatsızlık nedeniyle apareyin çıkarılmasının gerektiği, apareyin çıkarılmasını gerektirmeyen hafif ülseratif lezyonların MTH tipi Herbst grubunda, RMS tipi Herbst grubuna göre anlamlı derecede daha yaygın olduğu rapor edilmiştir. ${ }^{28}$

\section{Alt kesici dişlerde protrüzyon, labial diş eti çekilmesi ve spee eğrisinde artış}

Herbst apareyinin istenmeyen yan etkilerinden biri de alt kesici dişlerin protrüzyonudur. Bu etkinin, teleskop mekanizmasının ön dişler üzerine uyguladığı kuvvetler nedeniyle, ankraj kaybının sonucu olarak oluştuğu bilinmektedir. Kesici dişlerin protrüzyonunu, kullanılan ankraj sisteminden bağımsız olarak kontrol etmenin de zor olduğu bildirilmiştir. ${ }^{30} \mathrm{Bu}$ nedenle bu aparey kullanımında bu yan etki her zaman göz önüne alınmalıdır. 
Hareketli Herbst (mandibular akrilik splintin oral hijyenin sağlanması için çıkarılabilir olduğu Herbst tasarımı) apareyleri, sabit Herbst apareylerine göre daha az sıklıkla kullanıldıkları için alt kesici dişlerde daha az protrüzyona neden olduğu bildirilmiştir. ${ }^{20}$ Herbst apareyi uygulamaları sonrasında birçok çalışmada alt kesici dişlerde protrüzyon olduğu bildirilmiştir 2,6,31-42. El Fateh ve ark. tarafından ise kısa mandibular splint Herbst apareyleriyle yapılan tedavinin, total mandibular splint Herbst apareyleriyle yapılan tedaviden daha fazla oranda alt kesici dişlerde protrüzyona ve ankraj kaybına neden olduğu bildirilmiştir. ${ }^{43}$ Ancak Barnett ve ark. tarafından yapılan bir derlemede de belirtildiği gibi, bantlı ya da döküm tipi veyahut splint destekli Herbst çalışmaları incelendiğinde, mandibular kesici dişlerin mutlaka protrüzyon gösterdiği ve Herbst tedavisi ile ilgili kuvvet vektörleri göz önüne alındığında bu durumun şaşıtıcı olmadığı bildirilmiştir. ${ }^{44} \mathrm{Bu}$ protrüzyon miktarı, bazı durumlarda, Herbst tedavisi sonrasında önceden planlanmayan alt premolar çekimine götürecek kadar bile olabilmektedir. Resim 3a-d'de Herbst apareyi uygulaması sonucu aşırı derecede alt keser protrüzyonu oluşan bir vakaya ait ağız içi fotoğrafları ve sefalometrik filmleri gösterilmektedir. Alt keser protrüzyonu, Herbst apareyinin vertikal kuvvet yönünün molar dişlerdeki intrusiv etkisiyle birleşince spee eğrisinin aşırı derecede artışıyla da karşılaşılabilmektedir. Bu durum özellikle tedavi öncesinde hipodiverjan yapı gösteren bireylerde önemli bir problem oluşturabilmektedir. Resim 4a,b'de Herbst apareyi sonrası spee eğrisinin artması ve posterior okluzyonun açıldığı görülen örnek bir vaka sunulmaktadır. Bu durum Herbst tedavisi sonrası keser protrüzyonu sebebiyle diş çekimi gerektiren vakalarda kapanışın daha da derinleşmesi bakımından tedavi sürecini uzatabilmektedir.

Literatürde ortodontik tedavi ile protrüze edilmiş keserler sonucunda labial bölgede diş eti çekilmesi sıklıkla tartışılan bir konudur. Herbst apareyi ile tedavi sonrası oluşan alt kesici protrüzyonunun dişeti çekilmesine neden olmadığı rapor edilmiştir. ${ }^{35}$ Bock ve ark.'nın yaptığı bir çalışmada labial ve lingual yönlerden kombine bantlı Herbst apareyiyle tedavi edilen iki grupta, tedavi sonrasında dişeti çekilmesinin olmadığı belirtilmiştir. ${ }^{45}$ Pancherz ve Bjerklin'in 32 yıllık takip çalışmasında, bantlı Herbst ile tedavi sonrasında nüks görülen kesici dişlerde, küçük labial dişeti çekilmeleri tespit edilmiş ama bu durumun tedavi sırasında ve sonrasında dişlerin eğimindeki değişikliklerle ilişkili olmadığı bildirilmiştir. ${ }^{46}$ Yapılan başka bir çalışmada,
Sınıf II Bölüm 2 hastalarda, sabit tedavi ile kombine döküm Herbst apareyiyle tedavi sonrası, tüm daimi dişlerde labial yöndeki diş eti çekilmeleri değerlendirilmiş ve en yüksek insidans alt santral kesici dişler ve sağ üst premolar dişlerde tespit edilmiştir (\% 11,1 / $14,9)$. Bununla birlikte, uzun dönem retansiyon sonrası ( $\geq 24$ ay), labial yöndeki diş eti çekilmesinin ortalama miktarinin $0.06 \mathrm{~mm}$ olduğu ve bu durumun klinik öneminin düşük ve önemsiz kabul edilebileceği belirtilmiştir. ${ }^{47}$

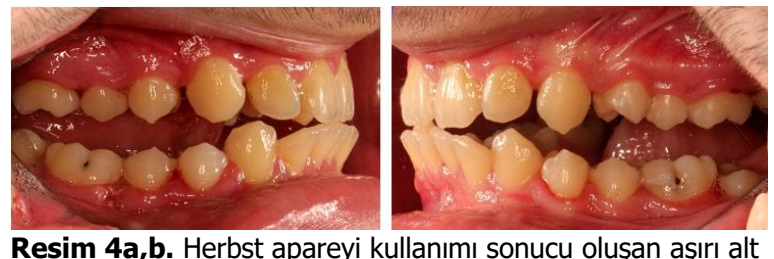

Resim 4a,b. Herbst apareyi kullanımı sonucu oluşan aşıı alt keser protruzyonu ve posterior spee eğrisinin aşırı derecede artması.
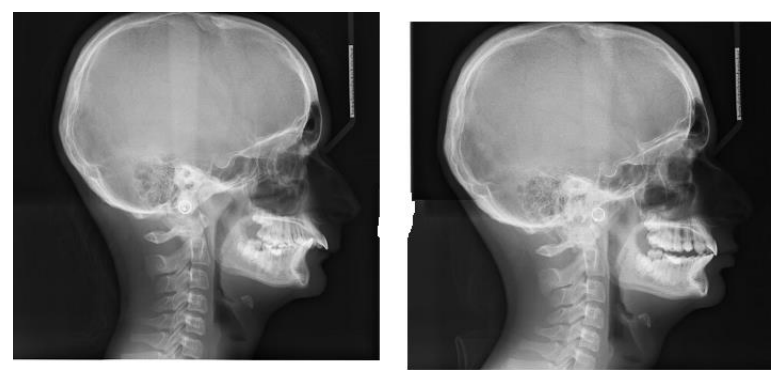

Resim 4c,d. Herbst apareyi kullanımı sonucu oluşan aşırı alt keser protrüzyonu ve posterior spee eğrisinin aşırı derecede arttığını gösteren başlangıç (c) ve aparey sonu (d) sefalometrik filmler

\section{Kök rezorpsiyonu}

Herbst apareyi uygulaması sırasında; uygulanan kuvvetin büyüklüğü, tedavinin süresi, dişlerin hareket etme yönleri, apikal yer değiştirme miktarı gibi kök rezorpsiyonu için bazı risk faktörleri olduğu bildirilmektedir. ${ }^{48}$ Literatürde bantlı Herbst apareyinin neden olduğu apikal kök rezorpsiyonunu değerlendiren dört çalışma bulunmaktadır:

Nasiopoulos ve ark.'nın yaptıkları çalışmalarında, alt ve üst premolar dişlerden alınan periapikal radyografilerde yapılan incelemeler sonucunda, üst ve alt premolar dişlerde istatistiksel olarak fark bulunmadığı belirtilmiş; ayrıca alt premolar dişlerle ilgili olarak, birinci premolar dişlerde ikinci premolar dişlerden daha fazla kök rezorpsiyonu olduğu bildirilmiştir. ${ }^{49}$ Kinzinger ve ark. tarafından ise hastalardan elde edilen panaromik radyografiler değerlendirildiğinde apikal kök rezorpsiyonundan en çok etkilenen dişlerin, alt birinci premolar ve üst birinci molar dişler olduğu rapor

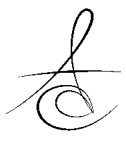


edilmiştir. ${ }^{50}$ Schwartz ve ark. tarafindan yapılan çalışmada ise, Herbst tedavisi uygulanan hastalarda 980 diş kökünün \%57,96'sında apikal kök rezorpsiyonu tespit edilmiş ve cinsiyet bakımından fark olmadığı bildirilmiştir. CBCT görüntüleri kullanılarak 3.molar dişler hariç tüm dişlerin apikal kök ucu ile kesici kenarı ya da tüberkül tepesi referans alınarak dişlerin uzunlukları değerlendirilmiştir. Sağ üst birinci molar dişin distobukkal kökünde, sol üst ikinci molar dişin distobukkal kökünde, sağ ve sol alt birinci molar dişin distal kökünde, sağ alt 2.molar dişin mesial ve distal köklerinde görülen rezorpsiyon miktarı istatistiksel olarak anlamlı bulunmuştur. Bununla birlikte meydana gelen rezorpsiyonların 0,5 mm'den küçük olduğu rapor edilmiştir. ${ }^{51}$

Herbst ve Jumper Twin Block Bite (JTBB) (twinblok apareyine bite jumping vidası eklenmiş tasarım) apareyleriyle yapılan başka bir çalışmada, tedavi sonrası alt ve üst kesici dişlerden elde edilen periapikal radyografiler kök rezorpsiyonu bakımından değerlendirilmiştir. Maksiller arkta kök rezorpsiyonu prevalansının mandibular arktan daha fazla olduğu; her iki grupta maksiller arkta \%56, Herbst ve JTBB gruplarında sırasıyla \%40 ve mandibular arkta \%39 olduğu bildirilmiştir. Dişler değerlendirildiğinde ise en çok rezorpsiyon görülen dişlerin maksiller santral kesici dişler, en az rezorpsiyon görülen dişlerin ise mandibular lateral kesici dişler olduğu rapor edilmiştir. ${ }^{52}$

\section{Temporomandibular eklemle ilgili} komplikasyonlar

Herbst apareyi yillarca temporomandibuler eklem (TME) üzerine olan etkileri sebebiyle eleştirilmiştir. Bu apareyinin rijit yapısı nedeniyle kondilin kronik olarak kompresyona uğradığı (baskılanma) ve bu nedenle ciddi kondiler rezorpsiyonun oluştuğu gerekçesiyle Herbst apareyi ile ilgili endişeler doğmuş ve bu nedenle uzun bir süre bu apareyin kullanımı tercih edilmemiştir. Kondilin dikey yönde rezorpsiyonunun okluzal splintlerle önüne geçilebileceği düşünülmüş ve birçok çalışmada bu nedenle splint destekli Herbst apareyi ve modifikasyonları kullanılmışır. Herbst apareyine okluzal ısırma bloğu ilavesinin, deney hayvanlarında şiddetli kondiler rezorpsiyonu veya diskin yer değiştirmesini önlediği tespit edilmiştir. ${ }^{53,54}$ Herbst tedavisinin etkisinin daha çok dentoalveolar olduğu ve bu durumda tedavinin çift kapanış (dual-bite) veya TME disfonksiyonuyla sonuçlanabileceği de belirtilmiştir. ${ }^{6}$

Tempromandibular eklemin detaylı olarak incelendiği ve bantlı Herbst apareyi ile tedavinin uzun dönem sonuçlarının değerlendirildiği Pancherz ve ark.'nın bir çalışmasında 6 ve 32 yıllık sonuçlar rapor edilmiştir. Herbst tedavisinden 6 yll sonra bir hastada osteoartrit bulguları görüldüğü; 32 yıllık takipte ise, ilave iki hastada osteoartrit bulgularının geliştiği belirlenmiştir. Altı yıllık takipte, iki hastada TME'de klik sesinin mevcut olduğu, ancak hastaların hiçbirinde TME ağrısı olmadığı bildirilmiştir. 32 yıllık takipte altı hastada TME'de klik sesi, bir hastada ise TME ağrısı olduğu belirlenmiş̧ir. Sonuç olarak, Herbst tedavisinin uzun süreli takip çalışmasında, hastaların TME bulgularının genel popülasyondaki bireylerle benzer olduğu, TME'de sadece küçük komplikasyonların tespit edildiği ve bu nedenle uzun dönemde Herbst apareyinin TME için zararlı olmadığı iddia edilmiştir. ${ }^{55}$

\section{Relaps}

Relaps genel olarak ortodontik anomalilerin tedavisinden sonra kaçınıımaz olarak, değişen oranlarda olmak üzere tüm vakalarda bildirilmektedir. Relapsın bir komplikasyon olarak değerlendirilmesi tartışmalı bir konu olmakla birlikte Herbst apareyi ile ilgili olanlar bu derlemede sunulmuştur.

Bondemark ve ark.'nın yaptığı sistematik derlemede, Sınıf II Bölüm 1 malokluzyonun Herbst apareyi ile tedavisiyle normal okluzyonun sağlandığı, uzun dönemde relapsın meydana geldiği, ancak bireysel düzeyde tahmin edilemediğini belirtmişlerdir (sınırlı kanıt nedeniyle). ${ }^{56}$ Flores-Mir ve ark.'nın yaptığı sistematik derlemede ise, Herbst tedavisi sonrası yapılan takip çalışmalarında, takip süresi boyunca tedavi edilen hastalarda relaps olduğu bildirilmiştir. ${ }^{38}$ Tedavi sonrası relaps, esas olarak dentoalveolar alanla sınırlı bulunmuştur. $57-59$ Molar ilişkide önemli miktarda relapsın tedavi sonrası dönemde oluştuğu ve bu değişikliğin üst molar dişlerin mesializasyonu nedeniyle olduğu belirtilmiştir. ${ }^{38,57}$ Tedavi sonrası Sınıf II relapsının, yetersiz dentoalveoler kompanzasyon ile olumsuz maksillomandibular büyüme paterninden kaynaklandığı da iddia edilmiştir. ${ }^{60}$

Pancherz ve Hansen Sınif II malokluzyonlu bir grup hastayı inceledikleri çalışmalarında, erken daimi dentisyonda Herbst apareyi ile tedavi edilen vakalarda, aktif tedaviden 6 ve 12 ay sonra, dentoalveoler ve iskeletsel relapsın, başarılı tedaviye etkisinin yaklaşık $\% 30$ olduğunu belirlemişlerdir. ${ }^{8}$ Bu çalışmada okluzal relapsın yüzde $90^{\prime}$ ının tedaviden sonraki ilk 6 ay içinde meydana geldiği tespit edilmiştir. Yapılan başka bir çalışmada ise, TME'de oluşan herhangi bir değişikliğin geçici olduğu ve bir yıl içinde relaps olduğu bildirilmiştir. ${ }^{61}$ 
Pancherz'in relapsın iskeletsel ve dental bileşenlerini değerlendirmek için yaptığı diğer bir çalışmasında, relaps gösteren 15 vaka ve 14 stabil vaka karşılaştırılmıştır. Lateral sefalometrik filmler tedaviden önce, hemen sonra, tedaviden altı ay sonra ve 5-10 yıl sonra elde edilmiştir. Her iki çenenin iskeletsel büyüme paterninin elverişli olduğu durumlarda okluzyonun relapsının etkilenmediği belirtilmiştir. Bununla birlikte, okluzal sonucu etkileyen durumun, tedavinin tamamlanmasından sonra meydana gelen önemli dental değişiklikler olduğu bildirilmiştir. Overjet ve molar ilişkilerdeki relapsın, tedaviyi takiben relaps grubundaki üst azı dişlerinin ve kesici dişlerin istatistiksel olarak anlamlı miktarda mesializasyonundan oluştuğu tespit edilmiştir. ${ }^{62}$

Literatürde Herbst apareyi ile tedavinin kısa süreli takibi neticesinde, Sınıf I dental-ark ilişkisinin elde edildiği durumlarda ve üst ve alt dişlerin interdigitasyonunun başarılı olduğu vakalarda relapsın olmadığı, interdigitasyonun başarısız olduğu vakalarda relaps eğilimi olduğu belirtilmiştir. ${ }^{6,8,32,58}$ Uzun süreli takip çalışmalarında ise, Sınıf II relapsın ana nedenlerinden olan devam eden dudak-dil disfonksiyon alışkanlığı37,62,63 ve başarısız interdigitasyonun 37,62,63 relapsa neden olduğu iddia edilmiştir.

Headgear-Herbst kombinasyon tedavisi üzerine uzun süreli bir takip çalışması, hem mandibular ilerlemede, hem de tedavi sırasında elde edilen mandibular uzunluktaki artışta önemli miktarda relaps olduğunu rapor etmiştir. ${ }^{64}$ Benzer şekilde Herbst apareyi ile ilgili diğer bir çalışmada da, kısa dönemde çene-bazal kaide ilişkilerinin düzeldiği, ancak uzun süreli takip sonrasında sagittal iskeletsel ilişkinin düzelmediği belirtilmiştir65.

Hansen ve ark.'nın yapmış oldukları çalışmalarında, tedavi sonrası birinci ( 6 ay) ve ikinci dönemde $(6,7$ yıl) vakaların çoğunda hem overbite hem de overjet artmış olsa da, bu durumun klinik olarak önemsiz olduğu belirtilmiştir. Relapsın Herbst tedavisinden sonra kesici diş pozisyonundaki değişim (rebound) ile açıklanabileceği bildirilmiştir. ${ }^{65}$ Herbst tedavisi sırasında alt keser dişlerin protrüzyonunun, tedaviden sonra kesici dişlerde çapraşıklıkla sonuçlanmadığı da bildirilmiştir. 46,66,67 Ancak tedavi sonrası birinci dönemde (6 ay), ark parametrelerinin kısalmasının hem maksiller hem de mandibuler dişlerin eğimlerinin değişmesinden kaynaklandığı düşünülmekte- dir.8,30,65

Relapsa etki eden diğer bir faktörün ise yüz tipi olduğu düşünülmüştür. Bock ve Pancherz retrognatik ve prognatik yüz tiplerine sahip Sınıf II Bölüm 1 hastalarda Herbst tedavisinin etkilerini kısa dönemde (12 ay sonra) ve uzun dönemde (39 ay sonra) incelemişlerdir. Çalışmalarında Herbst tedavisinin kısa dönemde başarılı olmasının yüz tipinden bağımsız olduğu bildirilmiştir. Retrognatik hastalarda mandibular büyüme değişikliklerinin açık bir şekilde dikey yönde olduğu, prognatik hastalarda ise anterior yönde olduğu tespit edilmiştir. Bu nedenle retrognatik yüz tipine sahip hastalarda, stabil bir Sınıf I okluzyona ulaşılmadığında, okluzal relaps için büyük bir risk oluştuğu belirtilmiştir. ${ }^{68}$

\section{SONUC}

Herbst apareyi, hasta kooperasyonuna gerek duymayan, farklı büyüme-gelişim dönemlerinde mandibular retrognatiye bağlı Sınıf II malokluzyonların tedavisinde kullanılabilen rijit bir sabit fonksiyonel aparey olmasına rağmen, ortodontik tedavi maliyetini arttırması ve aparey hazırlanması sırasında karmaşık laboratuvar safhası gerektirmesi gibi dezavantajları bulunmaktadır. Bununla birlikte Herbst apareyinin tedavi sırasında parçalarında kırılma meydana gelmesi, desimante olması, hastalarda gözlenen oral mukoza ülserasyonları ve kök rezorpsiyonları gibi komplikasyonları mevcuttur. Hasta konforunu arttırmak, istenmeyen yan etkileri elimine etmek amacıyla farklı aparey modifikasyonları tanıtılmasına rağmen, Herbst apareyinin tüm tiplerinde en az 1 komplikasyonla karşılaşıldığı görülmektedir. Bu komplikasyonların azaltılmasıyla ilgili olarak erken dönemde uygulanan Herbst tedavisinin hastanın yüksek biyolojik tolerans kapasitesi nedeniyle geç dönemde uygulanan fonksiyonel tedaviye göre daha avantajlı olduğu anlaşımakla birlikte, avantaj ve dezavantaj dengesi hasta için iyi değerlendirilerek bu tedavi tipi tercih edilmelidir.

Bu çalışma, çalışmayı yürüten tüm yazarlar tarafindan okunmuş ve onaylanmış orijinal bir çalışmadır. Herhangi bir yazar, kurum ya da kuruluş ile çıkar çatışması olmadığını belirtilmek isteriz.

\section{KAYNAKLAR}

1. Pancherz H. History, Background and Development of the Herbst Appliance. Semin Orthod 2003;9:311.

2. Pancherz $\mathrm{H}$. The mechanism of Class II correction in Herbst appliance treatment. A cephalometric investigation. Am J Orthod 1982;82:104-13.

3. Dagsuyu I.M., Baydas B. Sınıf II Bölüm 1 malokluzyonlu bireylerde fonksiyonel ortopedik tedavi etkilerinin aksiyografik ve sefalometrik 
yontemlerle incelenmesi. Atatürk Üniv Diş Hek Fak Derg 2011; 3: 196-212.

4. Zhang C. Herbst appliance anchored with miniscrews: Some unsettled questions. American Journal of Orthodontics and Dentofacial Orthopedics 2020;157:285-6.

5. Pancherz $\mathrm{H}$. Treatment of Class II malocclusions by jumping the bite with the Herbst appliance. Am J Orthod 1979;76: 423-42.

6. Pancherz $H$. The Herbst appliance-Its biologic effects and clinical use. Am J Orthod 1985;87:120.

7. Pancherz $H$, Hagg U. Dentofacial orthopedics in relation to somatic maturation. Am J Orthod 1985;88:273-87.

8. Pancherz $\mathrm{H}$, Hansen K. Occlusal changes during and after Herbst treatment. Eur J Orthod 1986;8:21528.

9. Wieslander L. Intensive treatment of severe Class II malocclusions with a headgear-Herbst appliance in the early mixed dentition. Am J Orthod 1984;86:113.

10. Wong GW, So LL, Hägg U. A comparative study of sagittal correction with the Herbst appliance in two different ethnic groups. Eur J Orthod 1997;19:195204.

11. McNamara JA, Howe RP. Clinical management of the acrylic splint Herbst appliance. Am J Orthod 1988;94:142-9.

12. Konik M, Pancherz $H$, Hansen K. The mechanism of Class II correction in late Herbst treatment. Am J Orthod Dentofacial Orthop 1997;112:87-91.

13. Ruf $S$, Pancherz $H$. Temporomandibular joint remodeling in adolescents and young adults during Herbst treatment: A prospective longitudinal magnetic resonance imaging and cephalometric radiographic investigation. Am J Orthod Dentofacial Orthop 1999;115:607-18.

14. Ruf S, Pancherz H. Dentoskeletal effects and facial profile changes in young adults treated with the Herbst appliance. Angle Orthod 1999;69:239-46.

15. Martina S, Di Stefano ML, Paduano FP, Aiello D, Valletta $R$, Paduano $S$. Evaluation of Profile Changes in Class II Individuals Treated by Means of Herbst Miniscope Appliance. Dent J (Basel) 2020; 8: 27.

16. Moresca AHK, de Moraes ND, Topolski F, FloresMir C, Moro A, Moresca RC, et al. Esthetic perception of facial profile changes in Class II patients treated with Herbst or Forsus appliances.
Angle Orthod 2020;90:571-7.

17. Moro A, Janson G, Moresca R, Freitas MR, Henriques JFC. Comparative study of complications during Herbst treatment with Cantilever Bite Jumper and removable mandibular acrylic splint. Dental Press J Orthod 2011;16:1-10.

18. Hägg $U$, Tse $E L$, Rabie $A B$, Robinson W.A. Comparison of splinted and banded Herbst appliances: treatment changes and complications. Aust Orthod J 2002;18:76-81.

19. Sanden E, Pancherz H, Hansen K. Complications during Herbst appliance treatment. J Clin Orthod 2004;38:130-3.

20. Valant JR, Sinclair PM. Treatment effects of the Hersbt appliance. Am J Orthod Dentofacial Orthop 1989;95:138-47.

21. Moro A, Janson G, Freitas MR, Henriques JFC, Petrelli NE, Lauris JP. Class II correction with the Cantilever Bite Jumper. A variant of the Herbst. Angle Orthod 2009;79:221-9.

22. Schiöth T, von Bremen J, Pancherz H, Ruf S. Complications during Herbst appliance treatment with reduced mandibular cast splints: a prospective, clinical multicenter study. J Orofac Orthop 2007;68:321-7.

23. Wiechmann D, Vu J, Schwestka-Polly R, Helms $\mathrm{HJ}$, Knösel M. Clinical complications during treatment with a modified Herbst appliance in combination with a lingual appliance. Head Face Med 2015;11:31.

24. Manni A, Cozzani M, Mazzotta L, Fiore VP, Mutinelli S. Acrylic splint Herbst and Hanks telescoping Herbst: a retrospective study of emergencies, retreatments, treatment times and failures. Int Orthod 2014;12:100-10.

25. O'Brien K, Wright J, Conboy F. Sanjie Y, etal. Effectiveness of treatment for class II malocclusion whith the Herbst or Twin Block appliances: a randomized, controlled trial. Am J Orthod 2003;124:128-37.

26. Kanuru R, Bhasin V, Khatri A, Dodda K, Singh E, Grover S. Comparison of Complications in Removable Mandibular Acrylic Splint and Cantilever Herbst for Management of Class II Malocclusion: A Retrospective Study. J Contemp Dent Pract 2017;18:363-5.

27. Silva JF, Gerszewski C, Moresca RC, Correr GM, Flores-Mir C, Moro A. Retrospective study of clinical complications during orthodontic treatment with either a removable mandibular acrylic splint

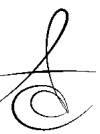


Herbst or with a cantilever Herbst. Angle Orthod 2015;85:64-71.

28. Manni A, Mutinelli S, Cerruto C, Giraudo P, Romano $R$, Cozzani M. Comparison of complications in the conventional telescopic Herbst rod and tube and Manni telescopic Herbst: A retrospective clinical study. Angle Orthod 2018;88:377-83.

29. Favale M, Di Luzio C, Caputo M, Bellisario A, Squillace $F$. The effectiveness of Herbst appliance in II class malocclusion. Webmed Central orthodontics 2017;8:1-5.

30. Pancherz $\mathrm{H}$, Hansen K. Mandibular anchorage in Herbst treatment. Eur J Orthod 1988;10:149-64.

31. Pancherz $H$. The effects, limitations, and long-term dentofacial adaptations to treatment with the Herbst appliance. Semin Orthod 1997;3:232-43.

32. Almeida MR, Henriques JFC, Almeida RR, Ursi W, McNamara JA Jr.. Short-term treatment effects produced by the Herbst appliance in the mixed dentition. Angle Orthod 2005;75:540-7.

33. Hagg U, Pancherz H. Dentofacial orthopaedics in relation to chronological age, growth period and skeletal development. An analysis of 72 male patients with Class II division 1 malocclusion treated with the Herbst appliance. Eur J Orthod 1988; 10:169-76.

34. Gerszewski C. Topolski F. Correr G. Gomes R. Dentoalveolar Evaluation of Lower Incisors by CBCT after Treatment with Herbst Appliance. Braz Dent J 2018;29:562-8.

35. Ruf S, Hansen K, Pancherz H. Does orthodontic proclination of lower incisors in children and adolescents cause gingival recession? Am J Orthod Dentofac Orthop 1998;114:100-6.

36. Kucukkeles N, Sandalli T. Cephalometric evaluation of the therapeutic effects of the Herbst appliance in the treatment of Class II. Div I. malocclusion. J Marmara Univ Dent Fac 1992;1:230-6.

37. Croft RS, Buschang PH, English JD, Meyer R. A cephalometric and tomographic evaluation of Herbst treatment in the mixed dentition. Am J Orthod Dentofacial Orthop 1999;116:435-43.

38. Flores-Mir C. Ayeh A. Goswani A. and Charkhandeh S. Skeletal and dental changes in class II division 1 malocclusions treated with splinttype Herbst appliances. A systematic review. Angle Orthod 2007;77:376-81.

39. Ruf $\mathrm{S}$, Pancherz $\mathrm{H}$. Orthognathic surgery and dentofacial orthopedics in adult Class II Division 1 treatment: mandibular sagittal split osteotomy versus Herbst appliance. Am J Orthod Dentofacial Orthop 2004;126:140-52.

40. Sidhu MS, Kharbanda OP, Sidhu SS. Cephalometric analysis of changes produced by a modified Herbst appliance in the treatment of Class II division 1 malocclusions. $\mathrm{Br}$ J Orthod 1995;22:1-12.

41. Ursi WJS, McNamara Junior J, Martins DR. Clinical alteration of a growing face: a cephalometric comparison of class II patients treated with cervical headgear, Frankel (FR-2) and Herbst appliances. Rev Dent Press Ortodon Ortop Maxilar 1999;4: 77-108.

42. Franchi L, Baccetti T, McNamara JA Jr. Treatment and posttreatment effects of acrylic splint Herbst appliance therapy. Am J Orthod Dentofacial Orthop 1999;115:429-38.

43. El-Fateh T, Ruf S. Herbst treatment with mandibular cast splints-revisited. Angle Orthod 2011;81:820-7.

44. Barnett GA, Higgins DW, Major PW, Flores-Mir C. Immediate Skeletal and Dentoalveolar Effects of the Crown-or Banded Type Herbst Appliance on Class II division 1 Malocclusion: A Systematic Review. Angle Orthod 2008; 78:361-9.

45. Bock NC, Ruf S, Wiechmann D, Jilek T. Herbst plus Lingual versus Herbst plus Labial: a comparison of occlusal outcome and gingival health. Eur J Orthod 2016; 38:478-84.

46. Pancherz $H$, Bjerklin K. Mandibular incisor inclination, tooth irregularity, and gingival recessions after Herbst therapy: a 32-year followup study. Am J Orthod Dentofacial Orthop 2014;146: 310-8.

47. Bock NC, Ruehl J, Ruf S. Prevalence, magnitude, and incidence of labial gingival recession with Herbst-multibracket appliance treatment: A retrospective cohort study. Angle Orthod 2019;89: 535-43.

48. Weltman B, Vig KW, Fields HW, Shanker S, Kaizar EE. Root resorption associated with orthodontic tooth movement: a systematic review. Am J Orthod Dentofacial Orthop 2010;137:462-76.

49. Nasiopoulos AT, Athanasiou AE, Papadopoulos MA, Kolokithas G, Ioannidou I. Premolar root changes following treatment with the banded herbst appliance. J Orofac Orthop 2006;67:261-71.

50. Kinzinger GS, Savvaidis S, Gross U, Gülden N, Ludwig B, Lisson J. Effects of Class II treatment with a banded Herbst appliance on root lengths in 
the posterior dentition. Am J Orthod Dentofacial Orthop 2011;139:465-9.

51. Schwartz JP, Raveli TB, Almeida KC, SchwartzFilho HO, Raveli DB. Cone beam computed tomography study of apical root resorption induced by Herbst appliance. J Appl Oral Sci 2015;23:47985.

52. Taha MA, Hammad SM. A radiographic comparison of apical root resorption between Herbst and Jumper twin block bite appliances. Egyptian Orthodontic Journal 2011; 39:15-28.

53. Voudouris JC, Woodside DG, Altuna G, Kuftinec MM, Angelopoulos G, Bourque P J. Condyle-fossa modifications and muscle interactions during Herbst treatment, Part 1. New technological methods. Am J Orthod Dentofacial Orthop 2003;123:604-13.

54. Voudouris JC, Woodside DG, Altuna G, Angelopoulos G, Bourque PJ, Lacouture CY. Condyle-fossa modifications and muscle interactions during Herbst treatment, Part 2. Results and conclusions. Am J Orthod Dentofacial Orthop 2003;124:13-29.

55. Pancherz $H$, Salé $H$, Bjerklin K. Signs and symptoms of TMJ disorders in adults after adolescent Herbst therapy: a 6-year and 32-year radiographic and clinical follow-up study. Angle Orthod 2015;85(5):735-42.

56. Bondemark L, Holm AK, Hansen K, Axelsson S, Mohlin B, Brattstrom V, Paunlin G, Pietila T. Longterm stability of orthodontic treatment and patient satisfaction: a systematic review. Angle Orthod 2007;77:181-91.

57. Franchi L, Baccetti T, McNamara Jr JA. Treatment and posttreatment effects of acrylic splint Herbst appliance therapy. Am J Orthod Dentofacial Orthop 1999;115(4):429-38.

58. Pancherz $\mathrm{H}$. The effect of continuous bite jumping on the dentofacial complex: a follow-up study after Herbst appliance treatment of Class II malocclusions. Eur J Orthod 1981;3:49-60.

59. Jakobsone G, Latkauskiene D, McNamara JrJA. Mechanisms of Class II correction induced by the crown Herbst appliance as a single-phase Class II therapy: 1 year follow-up. Prog Orthod 2013;14:27.

60. Pancherz H, Bjerklin K, Hashemi K. Late adult skeletofacial growth after adolescent Herbst therapy: a 32-year longitudinal follow-up study. Am J Orthod Dentofacial Orthop 2015;147:19-28.
61. Pancherz $H$, Fischer $S$. Amount and Direction of Temporomandibular Joint Growth Changes in Herbst Treatment: A Cephalometric Long-term Investigation. Angle Orthod 2003; 73: 493-501.

62. Pancherz $\mathrm{H}$. The nature of Class II relapse after Herbst appliance treatment: a cephalometric longterm investigation. Am J Orthod Dentofacial Orthop 1991; 100: 220-33.

63. Pancherz $H$, Bjerklin $K$, Lindskog-Stokland $B$, Hansen K. Thirty-two-year follow-up study of Herbst therapy: a biometric dental cast analysis. Am J Orthod Dentofacial Orthop 2014;145:15-27.

64. Wieslander L. Long-term effect of treatment with the headgear- Herbst appliance in the early mixed dentition. Stability or relapse? Am J Orthod Dentofacial Orthop 1993;104:319-29.

65. Hansen K, Pancherz $H$. Long-term effects of Herbst treatment in relation to normal growth development: a cephalometric study. Eur J Orthod, 1992;14: 285-95.

66. Hansen K, Koutsonas TG, Pancherz H. Long-term effects of Herbst treatment on the mandibular incisor segment: a cephalometric and biometric investigation. Am J Orthod Dentofacial Orthop 1997;112: 92-103.

67. Latkauskiene D, Jakobsone G, McNamara JA. A prospective study on the clinical effectiveness of the stainless steel crown Herbst appliance. Prog Orthod 2012;13:100-108.

68. Bock N, Pancherz H. Herbst Treatment of Class II division 1 Malocclusions in Retrognathic and Prognathic Facial Types: A Cephalometric Longterm Retrospective Study. Angle Orthod 2006; 76:930-41.

\section{Sorumlu Yazarın Yazışma Adresi}

Prof. Dr. Elçin ESENLİK

Akdeniz Üniversitesi Diş Hekimliği Fakültesi, Ortodonti AD, Antalya, TÜRKİYE

e-mail: elcinesenlik@gmail.com. 